\title{
Update on Irritable Bowel Syndrome Program of Research
}

\author{
Margaret Heitkemper ${ }^{1} \cdot$ Monica Jarrett $\cdot$ Jun, Sang-Eun ${ }^{2}$ \\ ${ }^{1}$ Department of Biobehavioral Nursing \& Health Systems, University of Washington, Seattle, USA \\ ${ }^{2}$ College of Nursing, Keimyung University, Daegu, Korea
}

\begin{abstract}
Purpose: This article provides an update and overview of a nursing research program focused on understanding the pathophysiology and management of irritable bowel syndrome (IBS). Methods: This review includes English language papers from the United States, Europe, and Asia (e.g., South Korea) from 1999 to 2013. We addressed IBS as a health problem, emerging etiologies, diagnostic and treatment approaches and the importance of a biopsychosocial model. Results: IBS is a chronic, functional gastrointestinal disorder characterized by recurrent episodes of abdominal pain and alterations in bowel habit (diarrhea, constipation, mixed). It is a condition for which adults, particularly women ages $20-45$, seek health care services in both the United States and South Korea. Clinically, nurses play key roles in symptom prevention and management including designing and implementing approaches to enhance the patients' self-management strategies. Multiple mechanisms are believed to participate in the development and maintenance of IBS symptoms including autonomic nervous system dysregulation, intestinal inflammation, intestinal dysbiosis, dietary intolerances, alterations in emotion regulation, heightened visceral pain sensitivity, hypothalamic-pituitary-adrenal dysregulation, and dysmotility. Because IBS tends to occur in families, genetic factors may also contribute to the pathophysiology. Patients with IBS often report a number of co-morbid disorders and/or symptoms including poor sleep. Conclusion: The key to planning effective management strategies is to understand the heterogeneity of this disorder. Interventions for IBS include non-pharmacological strategies such as cognitive behavior therapy, relaxation strategies, and exclusion diets.
\end{abstract}

Key words: Irritable bowel syndrome, Adults, Etiology, Diagnosis, Treatment

\section{INTRODUCTION}

Symptom science is emerging as an important opportunity to meld nursing science conducted at the bedside or ambulatory care centers with that conducted at the bench. Clinically nurses play key roles in symptom prevention and management including designing and implementing strategies to enhance self-management strategies for patients and their caregivers. Using clinical observations and careful description as well as randomized clinical trials, the field of nursing science has contributed importantly to each of these components. At this time we are poised to delve even further as we test the links between basic science, pathobiology, behavior, and symptoms using newer techniques including genomics, proteomics, and metabolomics. Although the study of symptoms and clinical phenotype have long been the focus of nursing research, the label of 'symptom science' offers the opportunity for nursing scientists to view the work we do within a broader framework and to incorporate additional tools from other disciplines. In this paper we present an update on our work focused on a common functional gastrointestinal (FGID) disorder, irritable bowel syndrome (IBS).

\section{IRRITABLE BOWEL SYNDROME: A HEALTH PROBLEM}

Approximately 10-20\% of adults in the United States (US) and 6.69.0\% in South Korea (Park et al., 2010) experience chronic abdominal symptoms (abdominal pain/discomfort and associated bowel changes

Address reprint requests to : Margaret Heitkemper

School of Nursing, Box 357266, University of Washington, Seattle, WA, USA 98195-7266

Tel: +1-206-543-1091 Fax: +1-206-543-4771 E-mail:heit@uw.edu

Received:September 9, 2013 Revised:September 17,2013 Accepted:September 23, 2013 
[constipation and/or diarrhea]) compatible with a diagnosis of IBS (Drossman et al., 2006). In the US as well as other western countries, women seek health care services disproportionately more than men. The public health impact of IBS in the US is enormous with direct costs totaling approximately $\$ 1.35$ billion/year and indirect costs about 205 million/year (Inadomi et al., 2003). In South Korea, the direct medical costs were approximately $\$ 96$ million (108 billion KRW) in 2007 by the National Health Insurance Statistical Yearbook (Jung et al., 2011) and it is increasing

Despite the public health importance of FGIDs, progress defining the mechanism (s) accounting for symptoms (particularly pain) and delineating effective pain interventions has been slow. In part, because the definition of the disorder has changed over time (Rome criteria), is symptom-based, and is open to interpretation (Camilleri \& Talley, 2004; Gwee \& Ghoshal, 2010). Although phenotype-based diagnosis in IBS has been suggested to be valid, studies have questioned these findings (Camilleri \& Talley; Gwee \& Ghoshal; Moayyedi \& Ford, 2011). Our work to date underscores the challenges with phenotype-based diagnosis (Cain et al., 2006; Cain, Jarrett, Burr, Hertig, \& Heitkemper, 2007; Goo et al., 2012). Yet, phenotype-based categorization commonly dictates what is done clinically for these patients. For example, the lack of non-invasive biomarkers that discriminate among IBS, inflammatory bowel disease (IBD), cancer, and celiac disease in patients and healthy individuals contributes to the number of diagnostic procedures and clinical burden of chronic GI pain condition (Halpert, 2010). Thus, as noted by leaders in IBS, use of clinical phenotyping alone is not enough (Camilleri \& Talley; Gwee \& Ghoshal; Moayyedi \& Ford). They advocate development of biomarkers to identify pathophysiological mechanisms in IBS to elucidate the etiology, define the diagnosis, predict the prognosis, speed up development of treatment/management strategies, and reduce IBS-related costs.

The primary hypothesis of our on- going studies is that factors contributing to the experience of pain and life disruption in IBS vary among subgroups distinguished by factors other than stool pattern. Understanding those factors and how they interact concurrently is central and essential to development of interventions to reduce or alleviate pain and disability and enhance quality of life (Chitkara, van Tilburg, Blois-Martin, \& Whitehead, 2008). By improving knowledge of the pathobiology operative in IBS, our results will likely impact future therapeutic efforts and symptom management.

\section{EMERGING VIEW OF THE ETIOLOGY OF IBS}

Studies suggest an interplay among increased GI permeability ("leaky gut'), abnormalities in the composition of the GI microbiota (bacteria, their genomes and interaction with the host), altered immune responses, autonomic dysfunction, altered bile acid metabolism, and psychological distress lead to the symptoms and the subsequent functional impact of IBS (Camilleri, Lasch, \& Zhou, 2012). Recent studies of pathobiological markers support the hypotheses that IBS can develop from centrally dominant factors such as early adverse events/stress (Bradford et al., 2012), significant life events with moderate stress in adults (Alonso et al., 2008), luminal factors (infection, alterations in the GI microbiota [dysbiosis]) triggering immune activation (Hughes et al., 2013), or all three. In some these occur concurrently or interactively. For example, stress can increase or slow GI motility (Konturek, Brzozowski, \& Konturek, 2011) thereby modifying the microbiota with subsequent immune activation that generates symptoms. Increased permeability may be due to genetic susceptibility in the inflammatory response and/or dysbiosis leading subsequent host immune responses and symptoms. Based on preliminary data and the literature, our group has started to focus on additional mechanisms that may distinguish groups, clarify pathophysiology, and lead to more personalized care.

\section{Microbiome}

The largest microbial mass in the body is found in the GI tract, with estimates of $>10^{13}$ organisms present. Recent advances have identified novel associations of the gut microbiota with diverse diseases such as obesity, diabetes, rheumatoid arthritis, colorectal cancer, IBD, and IBS (Rajilic-Stojanovic et al., 2011). The microbiota is important in influencing immune and inflammatory responses within the GI tract, but may also influence systemic inflammatory responses. For example, in patients with type II diabetes altered proportions of Firmicutes and Bacteroidetes have been identified, along with increased levels of Gram-negative Proteobacteri (Larsen et al., 2010). These compositional changes may induce a pro-inflammatory state characterized by altered peripheral cytokine and bacterial lipopolysaccharide levels (Cani et al., 2008). In other studies microbiota composition was found to be related to severity of abdominal pain and stooling characteristics in children (Cani et al.; Saulnier et al., 2011). Visceral hyperalgesia is a common finding in IBS (approximately $25-50 \%$ ) and it may be related to microbiota composition 
(Camilleri et al., 2008). A current hypothesis is that abnormal microbiota activate mucosal innate immune responses which increase epithelial permeability, activate nociceptive sensory pathways and dysregulate the enteric nervous system (Arumugam et al., 2011; Jeffery et al., 2012).

Some commensal GI microbes are responsible for inflammation-related hyperalgesia via toll-like receptors whereas others can down regulate afferent pain signals from the gut (Aguilera, Vergara, \& Martínez, 2013; Amaral et al., 2008; Eutamene et al., 2007; Rodríguez-Fandiño, Hernández-Ruiz, \& Schmulson, 2010). The ability of microbes to alter pain perception and function underlies the use of probiotics (Moayyedi et al., 2010). Visceral sensitivity was heightened in mice receiving the IBS stool implant but not in those receiving healthy control implant suggesting that, at least in this model, changes in microbiota can be linked to visceral sensitivity. Additional factors that alter GI microbiota composition include stress and diet. Studies with rodents show the relationship of the microbiota to anxiety-like and depression-like behaviors (Bercik et al., 2011; Dinan \& Cryan, 2012). When compared to specific pathogen-free mice, germ-free mice display lower levels of anxiety-like behavior in response to water maze (Neufeld, Kang, Bienenstock, \& Foster, 2011). Infection and gut inflammation increase anxiety-like behavior in germ-free mice and probiotics can reduce the anxiety- and/or depressive-like behavior due to maternal separation, inflammation, and parasite infections (Foster \& McVey Neufeld, 2013). Some healthy adults show improvement in anxiety and depression after taking probiotics (Messaoudi et al., 2011). Knowledge about the links between intraluminal microbiota and pain sensitivity may be important in developing diagnostic tools as well as testing therapeutic approaches.

\section{Immune Function}

Under normal conditions the immune system including anti-inflammatory cytokines such as interleukin-10 (IL-10) plays central roles in maintaining immunologic tolerance to harmless substances in the intestine (Rodríguez-Fandiño et al., 2010). Inflammation can affect the function of smooth muscle and enteric nerves resulting in clinical symptoms of dysmotility and pain (Cremon et al., 2009). Studies indicate that in some IBS patients' low grade GI inflammation (without gross evidence of inflammation) relates to abdominal pain symptoms (Cremon et al.; Shulman, Eakin, Czyzewski, Jarrett, \& Ou, 2008). The Walkerton, Ontario Canada Campylobacter outbreak patients who were followed for a number of years post infection provide data linking infection, in- flammation, barrier function and IBS (Marshall et al., 2004). However, a convincing history of enteritis with onset of IBS is present only in a subset of patients with IBS (Jeffery, Quigley, Öhman, Simrén, \& O’Toole, 2012). The literature reveals inconsistencies as to whether pro- and/or anti-inflammatory cytokines are altered in IBS patients (Chang et al., 2012; Schmulson et al., 2012). It is our hypothesis that in adults with IBS in whom the etiology may be due to dysbiosis, an elevation in serum anti- and pro-inflammatory cytokines may signal either a state of chronic immune stimulation and/or an alteration in cytokine signaling pathways. A schematic of this potential pathway (for at least a subset of IBS patients) is shown in Figure 1.

\section{Diet}

Diet has long been proposed to contribute to the IBS symptoms. We noted in an early study that patients with IBS often identify food as an important cause of their symptoms. Adults and children with IBS complain of subjective food intolerance more commonly than healthy controls (Hsueh et al., 2011; Jarrett, Visser, \& Heitkemper, 2001). However, patients with IBS normally eat a diet similar to controls and the common reasons for diet-related symptoms (e.g., celiac disease) are not more prevalent in IBS than controls (Hyams, Hyman, \& Rasquin-Weber, 1999). An alternative explanation for IBS symptoms is that consumption of poorly digested fermentable foods (e.g., oligo-, di- and mono-saccharides, polyols [FODMAPs]) are acted on by colon bacteria resulting in increased gas production, abdominal pain/discomfort and potentially mood alterations. For example, adults with IBS-like symptoms and fructose malabsorption (that likely alters the GI microbiota composition) have higher depression scores than those without malabsorption (Ledochowski, Widner, Bair, Probst, \& Fuchs, 2000).

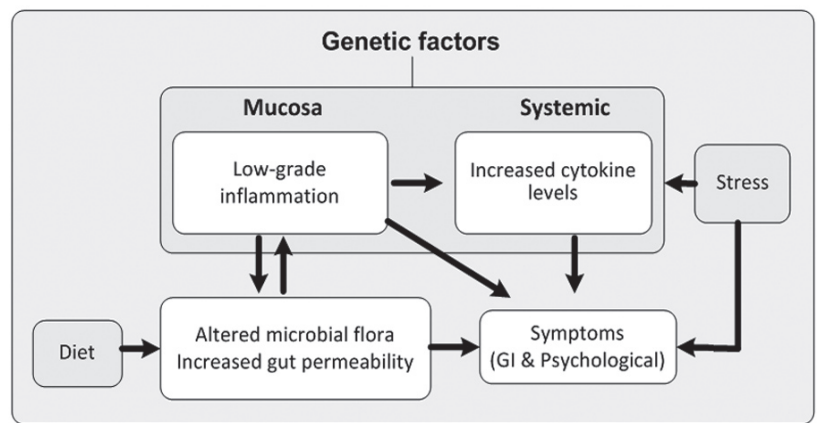

Figure 1. Proposed model for a subset of patients with Irritable Bowel Syndrome (IBS). 


\section{Genetics}

In western societies familial aggregation of IBS occurs (Heitkemper, Kohen, Jun, \& Jarrett, 2011). Genetic association approaches have been used to assess candidate pathways involved in IBS symptoms and the comorbidity of psychiatric conditions and psychological distress (Jarrett et al., 2007). Serotonin (5-HT) is an important neurochemical mediator and its availability is changed by alterations in 5-HT biosynthesis or reuptake. Serotonin reuptake transporter (SERT) acts as the major regulator of serotonergic neurotransmission by controlling intensity and duration of serotonergic signaling via reuptake of 5-HT into the synapse (Heitkemper et al.). The most frequently studied genetic variants of SERT, 5-HTTLPR, is a 43 base pair insertion/deletion polymorphism located in the promoter region, resulting in a short (s) and a long (l) allele. The s-allele of 5-HTTLPR is associated with higher vulnerability to psychological distress (Kumar, Ranjan, Mittal, \& Ghoshal, 2012). Others have shown that genetic variations are associated with higher pain ratings; whereas evidence for an association of 5-HTTLPR with specific bowel symptoms (diarrhea, constipation) of IBS is inconclusive (Kumar et al.). However, our preliminary data suggest that SERT polymorphisms are associated with diarrhea in those with high permeability indicating an association of SERT genotype with an endophenotype.

Tryptophan hydroxylase (TPH) is the rate-limiting enzyme of serotonin synthesis and has two isoforms, TPH1 and TPH2 (Walther \& Bader, 2003). TPH-2 is mainly expressed in the brain, while TPH1 is expressed both in the brain and in the periphery such as enterochromaffin (EC) cells in the gut (Walther \& Bader; Zill et al., 2007). Our recent work showed possible associations between TPHl gene polymorphisms and daily reporting of GI symptoms in European-American women with IBS (Jun, Kohen, Cain, Jarrett, \& Heitkemper, 2011). This study also showed possible associations between a TPH2 polymorphism and stool characteristics, such as diarrhea and constipation.

Given the potential role that inflammation may play in IBS, genes involved in cytokine production and/or receptors is another avenue for future research. Based on observations that the low-expressing IL-10 gene is associated with inflammatory bowel disease (IBD), Camilleri and Katzka (2012) reviewed the literature linking IL-10 gene polymorphisms with IBS. Two European studies provide conflicting evidence as to whether IL-10 genotype is associated with IBS. Such discrepancies may be related to differences in ethnic compositions or differences in the classification of IBS. IL-10R1s are expressed by many cells involved in the adaptive and innate immune system. IL-10R2s are expressed on epithelial cells. By testing the association of permeability, dysbiosis, cytokine levels, and symptoms with IL-10R1 and IL-10R2 polymorphisms we may be able to gain insights into the value of peripheral inflammatory targeted gene studies in IBS.

\section{Pain}

Evidence suggests that patients with IBS are more vigilant to pain-associated stimuli. One mechanism to look at pain sensitivity is to assess conditioned pain modulation (CPM) under laboratory conditions (Coëffier et al., 2010). In a pilot study we assessed CPM efficiency in women using a heat test stimulus and cold water condition stimulus in a laboratory between 8-10 am (follicular phase of menstrual cycle). Compared to healthy control women (ages 18-45), women with IBS reported more days with somatic pain/discomfort, psychological distress, fatigue, and feeling stressed. During the CPM baseline testing women with IBS reported greater pain sensitivity compared to the control group. In the IBS group, CPM efficiency was associated with the pain impact measure, daily abdominal pain/discomfort, psychological distress, in particular anxiety. Impaired CPM was present in a subset of IBS women suggesting that other factors such as alterations in luminal factors account for symptoms. These results suggest that there is an overall increase in selfreport of pain-related conditions, increase in thermal pain sensitivity, and for about a quarter of the women a decreased ability to inhibit pain sensation (Jarrett et al., 2009).

\section{Sleep}

Patients with IBS frequently report co-morbid pain-related conditions and daily fatigue as well as the interference of symptoms, quality of life and everyday functioning (Lackner et al., 2006). Among the most commonly reported symptoms accompanying IBS is poor sleep, including difficulty getting asleep, frequent awakenings during sleep, feeling un-refreshed in the morning, and poor overall sleep quality (Bellini et al., 2011; Heitkemper et al., 2005). Over the past 20 years, our research group has conducted a series of observational studies on sleep outcomes (self-report and objective) and symptoms in women with IBS. This work has shown that self-reported sleep disturbance and poor self-rated sleep quality in persons with IBS is associated with next-day GI symptoms including bowel pattern alterations and abdominal pain/discomfort 
(Jarrett, Heitkemper, Cain, Burr, \& Hertig, 2000). Such findings are further supported by studies with nurses and medical residents who report more GI symptoms when working shift work or nights (Nojkov, Rubenstein, Chey, \& Hoogerwerf, 2010).

Despite consistent evidence of disturbed sleep on self-reports objective measures of sleep have not consistently demonstrated sleep disturbance in persons with IBS. Polysomnography (PSG) differences in persons with IBS versus healthy controls include increased time to rapid eye movement (REM) sleep (Heitkemper et al., 2005) and decreased slow wave sleep (Rotem et al., 2003). Elsenbruch with Orr (Elsenbruch, Thompson, Hamish, Exton, \& Orr, 2002) reported that while self-report of disturbed sleep was greater in a group with IBS there were no differences in PSG variables (REM and non-REM sleep stages) when compared to a group of healthy controls. However, in a follow-up study these investigators reported that women with IBS who reported severe depressive symptoms and increased GI symptom severity were more likely to have sleep complaints and increased REM latency as compared to controls (Robert, Orr, \& Elsenbruch, 2004).

Many of the early sleep studies are limited by small sample sizes and lack of control for potential co-founding variables, most notably the 'first night' effect (Heitkemper et al., 2005). In an early study, the women with IBS had longer latency to stage II sleep on PSG than the healthy controls (Heitkemper et al.). This difference was present on both the first night and second night in the sleep laboratory. This finding may indicate a different response to the stress or novelty of the laboratory setting in women with IBS versus controls. Based on the hypothesis that sleep changes might reflect increased stress reactivity in a person with IBS, a follow-up study added the anticipation of public speaking stressor on PSG (i.e., on the third night at bedtime women were informed that they would have to give a short speech the following morning). As hypothesized, this stressor elicited several sleep differences between IBS and control women, including reduced sleep efficiency, increased time awake, and reduced time in REM (Heitkemper et al., 2012). This difference persisted even when data from the second night (or baseline) were controlled in the analyses. In addition we found elevations in serum cortisol but not adrenocorticotrophic hormone (ACTH) in women with IBS compared to controls (Heitkemper et al.). There remains the need for rigorous multi-night home or laboratory PSG studies of persons with IBS to determine the influence of sleep on symptoms and quality of life.

\section{DIAGNOSIS \& TREATMENT OF IBS}

With regard to developing diagnostic tools, our team has explored the utility of urine proteome characterization as a non-invasive biomarker. We used "shotgun" mass spectrometry to identify urine proteins in IBS and healthy control women. The differences in the urine proteome exist among symptomatically distinct groups of patients with IBS. However, like all body fluids there was large inter-and intra-individual variations (Jeffery et al., 2012). Several of the proteins that showed distinctive differences among IBS subgroups were ones involved in homeostasis of intestinal function. For example, mucin 1 (MUC1) and trefoil factor 3 (TFF3) are mucosal epithelial membrane-bound molecules synthesized by the intestinal goblet cells (Eutamene et al., 2007). Because the functional integrity of the intestine is important for defense against injury and pathogens, alterations in these proteins could result in mucosal inflammation and injury. As such the mucus layer and membrane-bound molecules such as TFF3 are the major components to protect/repair the epithelium. Thus, any change among these molecular components would affect the intestinal environment and result in increased permeability and subsequent inflammation. Increased permeability and elevations in tissue cytokines have been described in some patients with IBS (Aguilera et al., 2013). Research on the utility of urine proteomics as biomarkers for IBS is just beginning. Ideally, a proteomic biomarker would be one that distinguishes IBS subgroups from each other, healthy controls, and those with disease such as IBD. If such a biomarker can be found then samples from easily accessible body fluids such as urine, stool, or saliva could be collected non-invasively and tested.

Treatments for IBS include symptom-specific medications (ie, antispasmotic, antidiarrheal, anticonstipation, antidepressants, antibiotics), dietary management (e.g., fiber, elimination of trigger foods, probiotic) and psychological therapies (e.g., cognitive behavioral treatment [CBT], hypnosis, mindfulness meditation), herbal therapies, and acupuncture. Of these, only psychological therapies and a few drugs (e.g., lubiprostone, rifaximin, SSRIs) are recommended by national guidelines (e.g., American Gastroenterology Association [AGA], American College of Gastroenterology $[\mathrm{ACG}]$ ) for select patient subgroups (American College of Gastroenterology Task Force on Irritable Bowel Syndrome et al., 2009). In 2012, the British Dietetic Association guideline for IBS recommended the dietary elimination of malabsorptive foods (e.g., lactose, fermentable carbohydrates) and use of probiotics for IBS (McKenzie et al., 2012). The recommendations for psychological treatment are based on in-person 
CBT delivered by well-trained physician, psychologist, or nurse in a specialty clinic. We have demonstrated in our preliminary work that an intervention including nurse-delivered CBT provided over the telephone (Jarrett et al., 2009) for most of the sessions is equally effective as a 9-session in-person delivery. Ljótsson et al. (2011) effectively delivered a similar intervention through an internet platform thus expanding the potential impact of CBTs.

We have developed a nurse therapist-delivered intervention, Comprehensive Self-Management (CSM). The sessions start with what IBS is and is not (e.g., cancer) followed by sessions on breathing-relaxation techniques for stress reduction, dietary assessment to identify trigger foods, and cognitive restructuring of negative thoughts, tailored to the individual. Our studies have evaluated CSM delivered in-person as well as delivered mostly by telephone, and demonstrated that both delivery methods are effective in reducing symptom distress and enhancing QOL (Heitkemper et al., 2004; Jarrett et al., 2009). Our results are consistent with the meta-analyses for CBT in that therapy from a well-trained therapist can help patients to reduce symptoms and stress, and increase QOL (Lackner, Mesmer, Morley, Dowzer, \& Hamilton, 2004). A challenge to the dissemination of this evidenced-based CSM program is the lack of access to therapists qualified to provide nutritional counseling and CBT therapy as well as limited clinician time in primary and specialty clinics. This is particularly true in medically underserved areas where attendance at multiple appointments is not feasible, flexibility in scheduling is limited, and travel-related costs are expensive.

\section{CONCLUSION}

IBS should be viewed within a biopsychosocial model that considers pain, sleep, peripheral (luminal), immune activation, stress, autonomic nervous system dysregulation, genetics, as well as current and lifetime stress exposure. To date these measures have primarily been examined separately in patients' phenotypes using retrospective recall of bowel and discomfort symptoms. Such information is important to designing and tailor therapies.

\section{REFERENCES}

Aguilera, M., Vergara, P., \& Martínez, V. (2013). Stress and antibiotics alter luminal and wall-adhered microbiota and enhance the local expression of visceral sensory-related systems in mice. Neurogastroenterology and Motility, 25(8), e515-e529. http://dx.doi.org/10.1111/nmo.12154
Alonso, C., Guilarte, M., Vicario, M., Ramos, L., Ramadan, Z., Antolin, M., et al. (2008). Maladaptive intestinal epithelial responses to life stress may predispose healthy women to gut mucosal inflammation. Gastroenterology, 135(1), 163-172, e161.http://dx.doi.org/10.1053/j.gastro.20 08.03.036

Amaral, F. A., Sachs, D., Costa, V. V., Fagundes, C. T., Cisalpino, D., Cunha, T. M., et al. (2008). Commensal microbiota is fundamental for the development of inflammatory pain. Proceedings of the National Academy of Sciences of the United States of America, 105(6), 2193-2197. http:// dx.doi.org/10.1073/pnas.0711891105

American College of Gastroenterology Task Force on Irritable Bowel Syndrome, Brandt, L.J., Chey, W.D., Foxx-Orenstein, A.E. , Schiller, L.R., Schoenfeld, P.S., et al. (2009). An evidence-based position statement on the management of irritable bowel syndrome. The American Journal of Gastroenterology, 104 (Suppl 1), S1-S35. http://dx.doi.org/10.1038/ajg. 2008.122

Arumugam, M., Raes, J., Pelletier, E., Le Paslier, D., Yamada, T., Mende, D. R., et al. (2011). Enterotypes of the human gut microbiome. Nature, 473(7346), 174-180. http://dx.doi.org/10.1038/nature09944

Bellini, M., Gemignani, A., Gambaccini, D., Toti, S., Menicucci, D., Stasi, C., et al. (2011). Evaluation of latent links between irritable bowel syndrome and sleep quality. World Journal of Gastroenterology, 17(46), 5089-5096. http://dx.doi.org/10.3748/wjg.v17.i46.5089

Bercik, P., Park, A. J., Sinclair, D., Khoshdel, A., Lu, J., Huang, X., et al. (2011). The anxiolytic effect of bifidobacterium longum NCC3001 involves vagal pathways for gut-brain communication. Neurogastroenterology and Motility, 23(12), 1132-1139. http://dx.doi.org/10.1111/j.1365-29 82.2011.01796.x

Bradford, K., Shih, W., Videlock, E. J., Presson, A. P., Naliboff, B. D., Mayer, E. A., et al. (2012). Association between early adverse life events and irritable bowel syndrome. Clinical Gastroenterology and Hepatology, 10(4), 385-390, e381-e383. http://dx.doi.org/10.1016/j.cgh.2011.12.018

Cain, K. C., Headstrom, P., Jarrett, M. E., Motzer, S. A., Park, H., Burr, R. L., et al. (2006). Abdominal pain impacts quality of life in women with irritable bowel syndrome. The American Journal of Gastroenterology, 101(1), 124-132. http://dx.doi.org/10.1111/j.1572-0241.2006.00404.x

Cain, K. C., Jarrett, M. E., Burr, R. L., Hertig, V. L., \& Heitkemper, M. M. (2007). Heart rate variability is related to pain severity and predominant bowel pattern in women with irritable bowel syndrome. Neurogastroenterology and Motility, 19(2), 110-118. http://dx.doi.org/10.1111 /j.1365-2982.2006.00877.x

Camilleri, M., \& Katzka, D. A. (2012). Irritable bowel syndrome: Methods, mechanisms, and pathophysiology. Genetic epidemiology and pharmacogenetics in irritable bowel syndrome. American Journal of Physiology: Gastrointestinal and Liver Physiology, 302(10), G1075-G1084. http://dx.doi.org/10.1152/ajpgi.00537.2011

Camilleri, M., Lasch, K., \& Zhou, W. (2012). Irritable bowel syndrome: Methods, mechanisms, and pathophysiology. The confluence of increased permeability, inflammation, and pain in irritable bowel syndrome. American Journal of Physiology: Gastrointestinal and Liver Physiology, 303(7), G775-G785. http://dx.doi.org/10.1152/ajpgi.00155.2012

Camilleri, M., McKinzie, S., Busciglio, I., Low, P. A., Sweetser, S., Burton, D., et al. (2008). Prospective study of motor, sensory, psychologic, and autonomic functions in patients with irritable bowel syndrome. Clinical Gastroenterology and Hepatology, 6(7), 772-781. http://dx.doi.org/10.10 
16/j.cgh.2008.02.060

Camilleri, M., \& Talley, N. J. (2004). Pathophysiology as a basis for understanding symptom complexes and therapeutic targets. Neurogastroenterology and Motility, 16(2), 135-142. http://dx.doi.org/10.1111/j.13652982.2004.00516.x

Cani, P. D., Bibiloni, R., Knauf, C., Waget, A., Neyrinck, A. M., Delzenne, N. M., et al. (2008). Changes in gut microbiota control metabolic endotoxemia-induced inflammation in high-fat diet-induced obesity and diabetes in mice. Diabetes, 57(6), 1470-1481. http://dx.doi.org/10.2337 /db07-1403

Chang, L., Adeyemo, M., Karagiannides, I., Videlock, E. J., Bowe, C., Shih, W., et al. (2012). Serum and colonic mucosal immune markers in irritable bowel syndrome. The American Journal of Gastroenterology, 107(2), 262-272. http://dx.doi.org/10.1038/ajg.2011.423

Chitkara, D. K., van Tilburg, M. A., Blois-Martin, N., \& Whitehead, W. E. (2008). Early life risk factors that contribute to irritable bowel syndrome in adults: A systematic review. The American Journal of Gastroenterology, 103(3), 765-774, quiz 775. http://dx.doi.org/10.1111/j.15 72-0241.2007.01722.x

Coëffier, M., Gloro, R., Boukhettala, N., Aziz, M., Lecleire, S., Vandaele, N., et al. (2010). Increased proteasome-mediated degradation of occludin in irritable bowel syndrome. The American Journal of Gastroenterology, 105(5), 1181-1188. http://dx.doi.org/10.1038/ajg.2009.700

Cremon, C., Gargano, L., Morselli-Labate, A. M., Santini, D., Cogliandro, R. F, De Giorgio, R., et al. (2009). Mucosal immune activation in irritable bowel syndrome: Gender-dependence and association with digestive symptoms. The American Journal of Gastroenterology, 104(2), 392-400. http://dx.doi.org/10.1038/ajg.2008.94

Dinan, T. G., \& Cryan, J. F. (2012). Regulation of the stress response by the gut microbiota: Implications for psychoneuroendocrinology. Psychoneuroendocrinology, 37(9), 1369-1378. http://dx.doi.org/10.1016/ j.psyneuen.2012.03.007

Drossman, D. A., Corazziari, E., Delvaux, M., Spiller, R. C., Talley, N. J., Thompson, W. G., et al. (Eds.). (2006). Rome III: The functional gastrointestinal disorders (3rd ed.). McLean, VA: Degnon Associates.

Elsenbruch, S., Thompson, J. J., Hamish, M. J., Exton, M. S., \& Orr, W. C. (2002). Behavioral and physiological sleep characteristics in women with irritable bowel syndrome. The American Journal of Gastroenterology, 97(9), 2306-2314. http://dx.doi.org/10.1111/j.1572-0241.2002. 05984.x

Eutamene, H., Lamine, F., Chabo, C., Theodorou, V., Rochat, F., Bergonzelli, G. E., et al. (2007). Synergy between Lactobacillus paracasei and its bacterial products to counteract stress-induced gut permeability and sensitivity increase in rats. The Journal of Nutrition, 137(8), 1901-1907.

Foster, J. A., \& McVey Neufeld, K. A. (2013). Gut-brain axis: How the microbiome influences anxiety and depression. Trends in Neurosciences, 36(5), 305-312. http://dx.doi.org/10.1016/j.tins.2013.01.005

Goo, Y. A., Cain, K., Jarrett, M., Smith, L., Voss, J., Tolentino, E., et al. (2012). Urinary proteome analysis of irritable bowel syndrome (IBS) symptom subgroups. Journal of Proteome Research, 11(12), 5650-5662. http:// dx.doi.org/10.1021/pr3004437

Gwee, K. A., \& Ghoshal, U. C. (2010). The Rome criteria divides, distorts and dilutes the prevalence of irritable bowel syndrome. Saudi Journal of Gastroenterology, 16(3), 143-144. http://dx.doi.org/10.4103/1319-3767.65178

Halpert, A. D. (2010). Importance of early diagnosis in patients with irrita- ble bowel syndrome. Postgraduate Medicine, 122(2), 102-111. http:// dx.doi.org/10.3810/pgm.2010.03.2127

Heitkemper, M., Jarrett, M., Burr, R., Cain, K. C., Landis, C., Lentz, M., et al. (2005). Subjective and objective sleep indices in women with irritable bowel syndrome. Neurogastroenterology and Motility, 17(4), 523-530. http://dx.doi.org/10.1111/j.1365-2982.2005.00700.x

Heitkemper, M. M., Cain, K. C., Deechakawan, W., Poppe, A., Jun, S. E., Burr, R. L., et al. (2012). Anticipation of public speaking and sleep and the hypothalamic-pituitary-adrenal axis in women with irritable bowel syndrome. Neurogastroenterology and Motility, 24(7), 626-631, e270-e271. http://dx.doi.org/10.1111/j.1365-2982.2012.01915.x

Heitkemper, M. M., Jarrett, M. E., Levy, R. L., Cain, K. C., Burr, R. L., Feld, A., et al. (2004). Self-management for women with irritable bowel syndrome. Clinical Gastroenterology and Hepatology, 2(7), 585-596.

Heitkemper, M. M., Kohen, R., Jun, S. E., \& Jarrett, M. E. (2011). Genetics and gastrointestinal symptoms. Annual Review of Nursing Research, 29, 261-280.

Hsueh, H. F., Jarrett, M. E., Cain, K. C., Burr, R. L., Deechakawan, W., \& Heitkemper, M. M. (2011). Does a self-management program change dietary intake in adults with irritable bowel syndrome? Gastroenterology Nursing, 34(2), 108-116. http://dx.doi.org/10.1097/SGA.0b013e31 $821092 \mathrm{e} 8$

Hughes, P. A., Zola, H., Penttila, I. A., Blackshaw, L. A., Andrews, J. M., \& Krumbiegel, D. (2013). Immune activation in irritable bowel syndrome: Can neuroimmune interactions explain symptoms? The American Journal of Gastroenterology, 108(7), 1066-1074. http://dx.doi. org/10.1038/ajg.2013.120

Hyams, J. S., Hyman, P. E., \& Rasquin-Weber, A. (1999). Childhood recurrent abdominal pain and subsequent adult irritable bowel syndrome. Journal of Developmental and Behavioral Pediatrics, 20(5), 318-319.

Inadomi, J. M., Fennerty, M. B., \& Bjorkman, D. (2003). Systematic review: The economic impact of irritable bowel syndrome. Alimentary Pharmacology and Therapeutics, 18(7), 671-682.

Jarrett, M. E., Cain, K. C., Burr, R. L., Hertig, V. L., Rosen, S. N., \& Heitkemper, M. M. (2009). Comprehensive self-management for irritable bowel syndrome: Randomized trial of in-person vs. combined in-person and telephone sessions. The American Journal of Gastroenterology, 104(12), 3004-3014. http://dx.doi.org/10.1038/ajg.2009.479

Jarrett, M. E., Kohen, R., Cain, K. C., Burr, R. L., Poppe, A., Navaja, G. P., et al. (2007). Relationship of SERT polymorphisms to depressive and anxiety symptoms in irritable bowel syndrome. Biological Research for Nursing, 9(2), 161-169. http://dx.doi.org/10.1177/1099800407307822

Jarrett, M., Heitkemper, M., Cain, K. C., Burr, R. L., \& Hertig, V. (2000). Sleep disturbance influences gastrointestinal symptoms in women with irritable bowel syndrome. Digestive Diseases and Sciences, 45(5), 952-959.

Jarrett, M., Visser, R., \& Heitkemper, M. (2001). Diet triggers symptoms in women with irritable bowel syndrome. The patient's perspective. Gastroenterology Nursing, 24(5), 246-252.

Jeffery, I. B., O'Toole, P. W., Öhman, L., Claesson, M. J., Deane, J., Quigley, E. M., et al. (2012). An irritable bowel syndrome subtype defined by species-specific alterations in faecal microbiota. Gut, 61(7), 997-1006. http://dx.doi.org/10.1136/gutjnl-2011-301501

Jeffery, I. B., Quigley, E. M., Öhman, L., Simrén, M., \& O’Toole, P. W. (2012). The microbiota link to irritable bowel syndrome: An emerging story. 
Gut Microbes, 3(6), 572-576. http://dx.doi.org/10.4161/gmic.21772

Jun, S., Kohen, R., Cain, K. C., Jarrett, M. E., \& Heitkemper, M. M. (2011). Associations of tryptophan hydroxylase gene polymorphisms with irritable bowel syndrome. Neurogastroenterology and Motility, 23(3), 233239, e116. http://dx.doi.org/10.1111/j.1365-2982.2010.01623.x

Jung, H. K., Jang, B., Kim, Y. H., Park, J., Park, S. Y., Nam, M. H., et al. (2011). Health care costs of digestive diseases in Korea. The Korean Journal of Gastroenterology, 58(6), 323-331.

Konturek, P. C., Brzozowski, T., \& Konturek, S. J. (2011). Stress and the gut: Pathophysiology, clinical consequences, diagnostic approach and treatment options. Journal of Physiology and Pharmacology, 62(6), 591-599.

Kumar, S., Ranjan, P., Mittal, B., \& Ghoshal, U. C. (2012). Serotonin transporter gene (SLC6A4) polymorphism in patients with irritable bowel syndrome and healthy controls. Journal of Gastrointestinal and Liver Diseases, 21(1), 31-38.

Lackner, J. M., Gudleski, G. D., Zack, M. M., Katz, L. A., Powell, C., Krasner, S., et al. (2006). Measuring health-related quality of life in patients with irritable bowel syndrome: Can less be more? Psychosomatic Medicine, 68(2),312-320. http://dx.doi.org/10.1097/01.psy.0000204897.25745.7c

Lackner, J. M., Mesmer, C., Morley, S., Dowzer, C., \& Hamilton, S. (2004). Psychological treatments for irritable bowel syndrome: A systematic review and meta-analysis. Journal of Consulting and Clinical Psychology, 72(6), 1100-1113.

Larsen, N., Vogensen, F. K., van den Berg, F. W., Nielsen, D. S., Andreasen, A. S., Pedersen, B. K., et al. (2010). Gut microbiota in human adults with type 2 diabetes differs from non-diabetic adults. PLoS One, 5(2), e9085. http://dx.doi.org/10.1371/journal.pone.0009085

Ledochowski, M., Widner, B., Bair, H., Probst, T., \& Fuchs, D. (2000). Fructose- and sorbitol-reduced diet improves mood and gastrointestinal disturbances in fructose malabsorbers. Scandinavian Journal of Gastroenterology, 35(10), 1048-1052.

Ljótsson, B., Hedman, E., Andersson, E., Hesser, H., Lindfors, P., Hursti, T., et al. (2011). Internet-delivered exposure-based treatment vs. stress management for irritable bowel syndrome: A randomized trial. The American Journal of Gastroenterology, 106(8), 1481-1491. http://dx.doi. org/10.1038/ajg.2011.139

Marshall, J. K., Thabane, M., Garg, A. X., Clark, W., Meddings, J., \& Collins, S. M. (2004). Intestinal permeability in patients with irritable bowel syndrome after a waterborne outbreak of acute gastroenteritis in Walkerton, Ontario. Alimentary Pharmacology and Therapeutics, 20(11-12), 1317-1322. http://dx.doi.org/10.1111/j.1365-2036.2004.02284.x

McKenzie, Y. A., Alder, A., Anderson, W., Wills, A., Goddard, L., Gulia, P., et al. (2012). British Dietetic Association evidence-based guidelines for the dietary management of irritable bowel syndrome in adults. Journal of Humam Nutrition and Dietetics, 25(3), 260-274. http://dx.doi.org/ 10.1111/j.1365-277X.2012.01242.x

Messaoudi, M., Violle, N., Bisson, J. F., Desor, D., Javelot, H., \& Rougeot, C. (2011). Beneficial psychological effects of a probiotic formulation (Lactobacillus helveticus R0052 and Bifidobacterium longum R0175) in healthy human volunteers. Gut Microbes, 2(4), 256-261. http://dx. doi.org/10.4161/gmic.2.4.16108

Moayyedi, P., \& Ford, A. C. (2011). Symptom-based diagnostic criteria for irritable bowel syndrome: The more things change, the more they stay the same. Gastroenterology Clinics of North America, 40(1), 87-103. http://dx.doi.org/10.1016/j.gtc.2010.12.007

Moayyedi, P., Ford, A. C., Talley, N. J., Cremonini, F., Foxx-Orenstein, A. E., Brandt, L. J., et al. (2010). The efficacy of probiotics in the treatment of irritable bowel syndrome: A systematic review. Gut, 59(3), 325-332. http://dx.doi.org/10.1136/gut.2008.167270

Neufeld, K. M., Kang, N., Bienenstock, J., \& Foster, J. A. (2011). Reduced anxiety-like behavior and central neurochemical change in germ-free mice. Neurogastroenterology and Motility, 23(3), 255-264, e119. http:// dx.doi.org/10.1111/j.1365-2982.2010.01620.x

Nojkov, B., Rubenstein, J. H., Chey, W. D., \& Hoogerwerf, W. A. (2010). The impact of rotating shift work on the prevalence of irritable bowel syndrome in nurses. The American Journal of Gastroenterology, 105(4), 842-847.http://dx.doi.org/10.1038/ajg.2010.48

Park, D. W., Lee, O. Y., Shim, S. G., Jun, D. W., Lee, K. N., Kim, H. Y., et al. (2010). The differences in prevalence and sociodemographic characteristics of irritable bowel syndrome according to Rome II and Rome III. Journal of Neurogastroenterology and Motility, 16(2), 186-193. http:// dx.doi.org/10.5056/jnm.2010.16.2.186

Rajilic-Stojanovic, M., Biagi, E., Heilig, H. G., Kajander, K., Kekkonen, R. A., Tims, S., et al. (2011). Global and deep molecular analysis of microbiota signatures in fecal samples from patients with irritable bowel syndrome. Gastroenterology, 141(5), 1792-1801. http://dx.doi.org/10. 1053/ j.gastro.2011.07.043

Robert, J. J., Orr, W. C., \& Elsenbruch, S. (2004). Modulation of sleep quality and autonomic functioning by symptoms of depression in women with irritable bowel syndrome. Digestive Diseases and Sciences, 49(7-8), 1250-1258.

Rodríguez-Fandiño, O., Hernández-Ruiz, J., \& Schmulson, M. (2010). From cytokines to toll-like receptors and beyond-current knowledge and future research needs in irritable bowel syndrome. Journal of Neurogastroenterology and Motility, 16(4), 363-373. http://dx.doi.org/10.50 56/jnm.2010.16.4.363

Rotem, A. Y., Sperber, A. D., Krugliak, P., Freidman, B., Tal, A., \& Tarasiuk, A. (2003). Polysomnographic and actigraphic evidence of sleep fragmentation in patients with irritable bowel syndrome. Sleep, 26(6), 747-752.

Saulnier, D. M., Riehle, K., Mistretta, T. A., Diaz, M. A., Mandal, D., Raza, S., et al. (2011). Gastrointestinal microbiome signatures of pediatric patients with irritable bowel syndrome. Gastroenterology, 141(5), 17821791. http://dx.doi.org/10.1053/j.gastro.2011.06.072

Schmulson, M., Pulido-London, D., Rodriguez, O., Morales-Rochlin, N., Martinez-García, R., Gutierrez-Ruiz, M. C., et al. (2012). Lower serum IL-10 is an independent predictor of IBS among volunteers in Mexico. The American Journal of Gastroenterology, 107(5), 747-753. http://dx. doi.org/10.1038/ajg.2011.484

Shulman, R. J., Eakin, M. N., Czyzewski, D. I., Jarrett, M., \& Ou, C. N. (2008). Increased gastrointestinal permeability and gut inflammation in children with functional abdominal pain and irritable bowel syndrome. The Journal of Pediatrics, 153(5), 646-650. http://dx.doi.org/10. 1016/j.jpeds.2008.04.062

Walther, D. J., \& Bader, M. (2003). A unique central tryptophan hydroxylase isoform. Biochemical Pharmacology, 66(9), 1673-1680.

Zill, P., Büttner, A., Eisenmenger, W., Möller, H. J., Ackenheil, M., \& Bondy, B. (2007). Analysis of tryptophan hydroxylase I and II mRNA expression in the human brain: A post-mortem study. Journal of Psychiatric Research, 41(1-2), 168-173. http://dx.doi.org/10.1016/j.jpsychires.2005.05.004 